\title{
Smart Transportation Based Car Pooling System
}

\author{
Celesty Gedam ${ }^{1}$,Madhavi Sahare ${ }^{1, *}$,Rajneeshkaur Sachdeo ${ }^{2}$, and Nilima Kulkarni ${ }^{2}$ \\ ${ }^{1}$ School of Engineering, MIT ADT University, Pune, India. \\ ${ }^{2}$ School of Engineering, MIT ADT University, Pune, India.
}

\begin{abstract}
Sharing of car is Carpooling, so that multiple number of people can travel in single car. the use of car pooling reduces single individuals Travelling cost, reduces the fuel cost and reduces the number of cars. Due to the growth in the population there is inadequate transportation through their own car . Rather than using different mode of Transportation. It results in increasing number of Traffic on roads also increases pollution and increases time to travel to there destination. So by Smart transportation using car pooling system the individual can travel and share there rides with different people of a same destination. In this paper we have carried outs survey. By reviewing various Literature papers on carpooling it aims to reduce the number of cars by sharing the rides.
\end{abstract}

\section{Introduction}

Due to increasing amount of peoples every single people travel to their Destination alone in their own car. Travelling alone leads to increases individual fuel cost. The carpooling system merges multiple new people in a car which leads to meet new people in a car, reduces air pollution and noise pollution. The carpooling system save economy of every people as they share their rides also share the cost with the other member in car. It will stop endless Spending money in travel.Rather than using public transportation such as local train, buses and metros. The people can conveniently travel to there destination in the comfortably by giving same cost. The carpooling is the best ideas to reduces the traffic jams as it reduces the car on road. Safety is an important aspect in every means, so travelling with the different people is also a prior thing not all the people are comfortable to travel with the unknown people. For example, women are not feeling safe to travel with unknown people. So the carpooling system also provide ride of only woman.

\section{RelatedWork}

Nusrat et.al.[2] in this paper introduced the Euclidean distance for measuring the nearest vehicle. This system is based on 3 tier architecture where it had client tier, middle tier and database tier. In this system the users location can be tracked by the GPS. And after finding their location the system suggest the nearest vehicle to the users. In this paper for implementing the system the searching algorithm had also been used. This system helps to reduce empty seats of cars.

Fu-shiung et.al.[4] the main intention of this paper is to find the match between passenger and driver. Depending on their trajectories. In this system for solving the car pooling problem heuristic techniques has been applied, this techniques is used for searching and it also used a matching algorithm for allocating passenger to drivers car depending on their trajectories. The system had developed based on mobile platform as well as Google API. Based on matching algorithm and various different techniques the system was used in reduction of distance.

Mena et.al.[5] In this paper Semantic features used for car pooling system is based on the user trips. In this proposed system the two main techniques has been used that is route matching and the other is applied matching algorithm the route matching techniques is used for to find the match between the passenger based on their point of interest. It also apply machine learning cluster algorithm likek-mean and the density based spatial clustering of application with noise (DBSCAN) is applied for optimizing the rank between different match trips.

Raza Hasan et.al.[1] In this paper, author hadproposed the system smart peer car pooling system(SPCPS) for minimizing the number of cars and increasing the parking slot areas by using the linear programming problem it also uses the Dijkstra algorithm for finding shortestpath. In this paper optimal result is obtained from the dijkstra algorithm. The author had proposed the SPCPS system which is beneficial consuming fuel and also helped to improve the socialism.

Mattia et.al.[7] in this paper, it uses two types of techniques to propose carpooling system, first is learning-to-rank which is basically used for ranking model of the individual. Secondly they used learning algorithm in their system. The author proposed GOTOGETHER system which was used for carpooling 
system which uses machine learning ranking system. The system used twitter and foursquare dataset for the evaluation. Those dataset are used for the evaluation for the pattern and ride requests.

Fu-Shiung et.al.[6]This paper author had formulated the carpooling problems and formulated thier solutions.Using meta heuristic technique to evaluate differential evolution problem. To evaluate integration programming problem with combination of binary decision variable, it is using Differential Evolution technique in this system. Initially carpooling optimisation problem is formulated in the form of integer programming problem and then based on it different variants of differential evolution algorithms had been developed.

Shih-Chia Huang et.al.[7], the author had formulated carpool service problem (CSP). The paper had used Ant colony optimisation (ACO) algorithm, for the carpool service system. The author used ACO algorithm for choosing optimal path between ant colony and food source over graph.

\section{Methodology}

Car pooling system provides the benefits of sharing rides with different peoples. By surveying different papers, it is found that it uses heuristic searching techniques for searching the cars. By using Euclidean distance techniques, it finds the nearest car that has to be assigned to passenger. It usually uses Global Positioning System(GPS) for finding the locations of cars. In study it is found that, Route matching techniques are used in order to match drivers and passengers locations by using Google maps API, and then based on their route, driver is allocated to passenger. In most of carpooling system, it is observed that the Dijkstra algorithm is used for detecting the shortest route of destination of passenger. Dijkstra algorithm is usually used for detecting the optimal minimum path. It is found that is checks for maximum possibilities and then chooses the minimum route for thejourney.

\section{Car Pooling System}

After studying the paper[1][2][3] the generalized car pooling system is highlighted in fig.1. The system shows that, the passenger has to do registration, if already registered than directly has to logged into the system. All the passengers details are stored into the database then. Then passenger needs to enter the pickup and drop locations. If the location of passenger and driver matches, then the driver accepts the ride from the passenger. Security is prior thing in carpooling system. So as soon as the passenger is assigned with driver, the passenger has to share his/her live location, drivers details, car's details, other passenger details(if present) to their contacts. Then driver will check for optimal path. Driver has to accept the request of same destination. Depending upon the availability of seats and drop location, driver has to accept the ride.

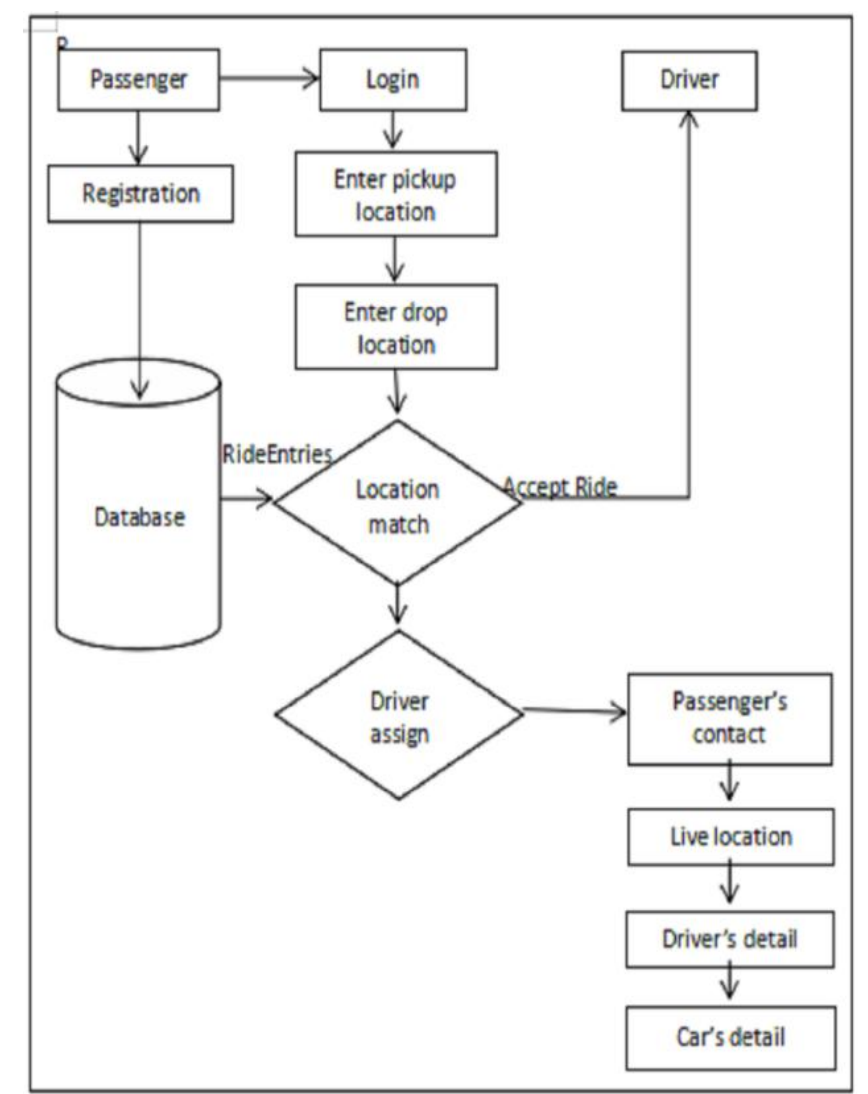

Fig.1. Flow diagram of carpooling system.

\section{Literature Survey}

\begin{tabular}{|c|c|c|c|c|}
\hline $\begin{array}{c}\text { Sr. } \\
\text { no. }\end{array}$ & Author & Methods & Features & Observation \\
\hline 1. & $\begin{array}{c}\text { Nusrat et. } \\
\text { al.[2] }\end{array}$ & $\begin{array}{c}\text { Searching } \\
\text { techniques } \\
\text { and } \\
\text { Euclidean } \\
\text { distance } \\
\text { measuring }\end{array}$ & $\begin{array}{c}\text { Euclidean } \\
\text { distance ride } \\
\text { sharing. }\end{array}$ & $\begin{array}{c}\text { Eliminate } \\
\text { space misuse }\end{array}$ \\
\hline 2. & $\begin{array}{c}\text { Fu- } \\
\text { Shiung } \\
\text { et.al.[4] }\end{array}$ & $\begin{array}{c}\text { Matching } \\
\text { algorithm } \\
\text { and } \\
\text { heuristic } \\
\text { searching } \\
\text { method } \\
\text { and google } \\
\text { distance }\end{array}$ & $\begin{array}{c}\text { Drivers cars } \\
\text { based } \\
\text { trajectories, } \\
\text { google } \\
\text { distance } \\
\text { matrix API } \\
\text { use to find } \\
\text { two distance } \\
\text { location. }\end{array}$ & $\begin{array}{c}\text { Distance } \\
\text { without } \\
\text { carpooling is } \\
48.5 \% \text { and } \\
\text { with } \\
\text { carpooling is } \\
22.6 \% \text { and } \\
\text { reduction of } \\
49.59 \% .\end{array}$ \\
\hline 3. & $\begin{array}{c}\text { Mena } \\
\text { at.al.[5] }\end{array}$ & $\begin{array}{c}\text { Route } \\
\text { matching } \\
\text { method } \\
\text { and } \\
\text { machine } \\
\text { learning } \\
\text { algorithm }\end{array}$ & $\begin{array}{c}\text { Use K- } \\
\text { means as } \\
\text { well as } \\
\text { density- } \\
\text { based } \\
\text { spatial } \\
\text { clustering } \\
\text { cluster for } \\
\text { the similar } \\
\text { trips and } \\
\text { most } \\
\text { optimal trip } \\
\text { to be joined } \\
\text { is assumed. }\end{array}$ & $\begin{array}{c}\text { Route } \\
\text { matching, } \\
\text { reducing the } \\
\text { number of trips } \\
\text { with 22.3\% } \\
\text { and machine } \\
\text { learning } \\
\text { techique 66\% } \\
\text { reduction }\end{array}$ \\
\\
\end{tabular}




\begin{tabular}{|c|c|c|c|c|}
\hline 4. & $\begin{array}{c}\text { Raza } \\
\text { Hasan } \\
\text { et.al.[1] }\end{array}$ & $\begin{array}{c}\text { Dijkstra } \\
\text { shortest } \\
\text { path } \\
\text { algorithm } \\
\text { and linear } \\
\text { programmi } \\
\text { ng } \\
\text { problem }\end{array}$ & $\begin{array}{l}\text { Dijkstra } \\
\text { algorithm is } \\
\text { used for } \\
\text { finding } \\
\text { shortest } \\
\text { distance, } \\
\text { linear } \\
\text { programmin } \\
\text { g used. }\end{array}$ & $\begin{array}{c}\text { Trajectories } \\
\text { between } \\
\text { passengers and } \\
\text { drivers are } \\
\text { determined. }\end{array}$ \\
\hline 5. & $\begin{array}{l}\text { Mattia } \\
\text { et.al.[7] }\end{array}$ & $\begin{array}{l}\text { Learning- } \\
\text { to-ran } \mathrm{k} \\
\text { and the } \\
\text { carpooling } \\
\text { learning } \\
\text { method }\end{array}$ & $\begin{array}{l}\text { LR, ranking } \\
\text { methods. }\end{array}$ & $\begin{array}{l}\text { Validity and } \\
\text { robustness. }\end{array}$ \\
\hline 6. & $\begin{array}{c}\text { Fu- } \\
\text { Shiung } \\
\text { et.al.[6] }\end{array}$ & $\begin{array}{c}\text { Differentia } \\
1 \\
\text { Evolution( } \\
\text { D.E) }\end{array}$ & $\begin{array}{c}\text { Discrete } \\
\text { differential } \\
\text { evolution } \\
\text { (D.E) } \\
\text { algorithm. }\end{array}$ & $\begin{array}{l}\text { Differential } \\
\text { evolution } \\
\text { problem is } \\
\text { formulated. }\end{array}$ \\
\hline 7. & $\begin{array}{c}\text { Shih-chia } \\
\text { Huag } \\
\text { et.al.[3] }\end{array}$ & $\begin{array}{c}\text { Ant colony } \\
\text { optimizatio } \\
\text { n (ACO) }\end{array}$ & $\begin{array}{l}\text { Optimal } \\
\text { path is } \\
\text { chosen } \\
\text { between the } \\
\text { ant colony } \\
\text { as well as } \\
\text { food source } \\
\text { over a graph } \\
\text { problem. }\end{array}$ & $\begin{array}{l}\text { ACPA with } \\
\text { path based } \\
\text { structure is } \\
\text { achieved. }\end{array}$ \\
\hline
\end{tabular}

\section{Conclusion}

The papers are chosen from the literature is studied in this paper. It is observed that most of the paper uses matching algorithm and Dijkstra algorithm for finding shortest distance. Thus we have discussed Matching algorithm and Dijkstra algorithm in detail. In this paper we have studied that Carpooling system helps in Reducing pollution, Fuel expense, Parking and Tolls. It is observed that there is much scope for the research in the car pooling system for ex. in reducing the time to find the required ride, calculating the minimum distance etc. In this paper we have tried to give reader an idea about complete car pooling process.

\section{References}

1. R.Hasan, A.H. Bhatti, M.S. Hayat, H.M. Gebreyohannes, S.I. Ali, A.J. Sayed, 2016 3rd MEC International Conference on Big Data and Smart City (ICBDSC), 1--6, (2016).

2. Farin, N. Jahan and Rimon, M. N. Ahsan Ali and Momen, Sifat and Uddin, M. Shorif and Mansoor, Nafees, 2016 International Workshop on Computational Intelligence (IWCI), 204--208, (2016).

3. Kalogirou, Kostas and Dimokas, Nikos and Tsami, Maria and Kehagias, Dionysis, 2018 IEEE 20th International Conference on High Performance Computing and Communications; IEEE 16th International Conference on Smart City; IEEE 4th
International Conference on Data Science and Systems (HPCC/SmartCity/DSS), 1271--1278, (2018).

4. Hsieh, F. Shiung, 2017 IEEE 31st International Conference on Advanced Information Networking and Applications (AINA), 972--978, (2017).

5. Samy, Mena and Elkorany, Abeer Mohamed, 2018 IEEE/ACM International Conference on Advances in Social Networks Analysis and Mining (ASONAM), 702--708, (2018).

6. Hsieh, F. Shiung and Zhan, Fu-Min, 2018 IEEE 42nd Annual Computer Software and Applications Conference (COMPSAC), 1, 577--582, (2018).

7. Campana, M. Giovanni and Delmastro, Franca and Bruno, Raffaele, 2016 IEEE 19th International Conference on Intelligent Transportation Systems (ITSC), 1856--1862, (2016).

8. Carrese, Stefano and Cipriani, Ernesto and Giacchetti, Tommaso and Sottile, Eleonora and Zamberlan, Leonardo, 2019 6th International Conference on Models and Technologies for Intelligent Transportation Systems (MT-ITS), 1--6, (2019).

9. Kulkarni and J. Amudha,Journal of Intelligent $1 \&$ Fuzzy Systems, 34, 1713-1722, (2018).

10. Zhang, Sijia and Jia, Shunping and Ma, Cunrui and Wang, Yuqiong, 2018 IEEE 3rd International Conference on Cloud Computing and Big Data Analysis (ICCCBDA, 280--284, (2018).

11. Opasanon, Sathaporn , 2018 Smart City Symposium Prague (SCSP), 1--7, (2018).

12. $\mathrm{Xi}, \mathrm{Xiaoming}$ and $\mathrm{Yu}, \mathrm{Zhilou}$ and Zhan, Zhaolei and Yin, Yilong and Tian, Cuihuan,IEEE Access, 7, 98061--98068, (2019).

13. Huang, Shih-Chia and Jiau, Ming-Kai and Lin, ChihHsiang, IEEE Transactions on Intelligent Transportation Systems,16, 352--364, (2014).

14. Lin, Chih-Hsiang and Jiau, Ming-Kai and Huang, Shih-Chia,2012 6th International Conference on New Trends in Information Science, Service Science and Data Mining (ISSDM2012), 266--271, (2012).

15. Bresciani, Chiara and Colorni, Alberto and Costa, Francesca , Alessandro and Studer, Luca, 2018 International Conference of Electrical and Electronic Technologies for Automotive, 1--4, (2018).

16. Elbery, Ahmed and EINainay, Mustafa and Rakha, Hesham, 2016 IEEE 12th International Conference on Wireless and Mobile Computing, Networking and Communications (WiMob), 1--8,(2016). 